\title{
CURSOS, PERCURSOS E TRANSCURSOS DA ANTROPOLOGIA NO PIAUÍ
}

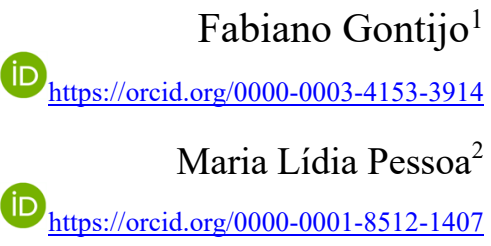

\section{RESUMO}

O artigo apresenta algumas reflexões sobre as particularidades da formação e do processo de consolidação do campo disciplinar da antropologia no estado brasileiro do Piauí. O que caracteriza e diferencia o perfil da formação da antropologia no Piaú em relação à antropologia nacional talvez seja a sua estreita associação com a história, com a literatura, com a psicanálise e com a arqueologia desde seus primórdios, mas também a feminilização da profissão e, enfim, o atendimento a demandas voltadas para o desenvolvimento sustentável.

Palavras-chave: Antropologia, Arqueologia, História, Gênero, Piauí.

\section{COURSES, PATHWAYS AND TRAJECTORIES OF ANTHROPOLOGY IN PIAUÍ}

\begin{abstract}
This text presents some preliminary considerations on the peculiarities of the formation and the processes of consolidation of the disciplinary field of anthropology in the Brazilian state of Piauí. What characterizes and differentiates the profile of the formation of anthropology in Piauí, when compared to the history of the "national anthropology" in Brazil, is its strict association with the disciplinary fields of history, literature, psychoanalysis, and archaeology from its beginnings, as well as its feminization and, finally its commitment with sustainable development.
\end{abstract}

Keywords: Anthropology, Archaeology, History, Gender, Piauí.

\section{CURSOS, SENDEROS Y TRAYECTORIAS DE LA ANTROPOLOGÍA EN PIAUÍ}

\section{RESUMEN}

Este texto presenta algunas consideraciones preliminares sobre las peculiaridades de la formación y los procesos de consolidación del campo disciplinario de la antropología en el estado brasileño de Piauí. Lo que caracteriza y diferencia el perfil de la formación de la antropología en Piauí, en comparación con la historia de la "antropología nacional" en Brasil, es su asociación estricta con los campos disciplinarios de la historia, la literatura, el psicoanálisis y la arqueología desde sus inicios, como, así como su feminización y, finalmente, su compromiso con el desarrollo sostenible.

Palabras clave: Antropología, Arqueología, Historia, Género, Piauí.

\footnotetext{
${ }^{1}$ Professor Titular de Antropologia da Faculdade de Ciências Sociais (FACS) e do Programa de Pós-Graduação em Antropologia (PPGA), Universidade Federal do Pará (UFPA), Doutor em Antropologia pela École des Hautes Études en Sciences Sociales, Frnaça, e Bolsista de Produtividade em Pesquisa do CNPq. Agradecimentos ao CNPq pela bolsa. E-mail: fgontijo2@hotmail.com.

2 Professora Titular de Antropologia, Departamento de Ciências Sociais (DCS) e Programa de Pós-Graduação em Antropologia (PPGAnt), Universidade Federal do Piauí (UFPI), Doutora em Teoria Literária pela Pontifícia Universidade Católica do Rio Grande do Sul e Membro da Associação de Psicanálise do Piauí (CEPP). E-mail: lidianoronha@ufpi.edu.br.
} 
Compreender os processos de constituição social das diferenças culturais no tempo (histórico e pré-colonial) e no espaço (regional), com a finalidade de promover a formação da cidadania cultural, pode ser considerado o objetivo (e objeto) maior dos estudos antropológicos. Partindo dessa preocupação com as diferenças e as alteridades, o campo disciplinar da antropologia foi-se instituindo no Brasil quase que paralelamente a sua constituição nos Estados Unidos, na GrãBretanha, na França e na Alemanha (Bart et al., 2005), "tropicalizando-se" e adaptando às realidades brasileiras os modelos disciplinares desses países (Cardoso de Oliveira, 1993; Peirano, 2005; Ribeiro, 2006) $)^{3}$.

Ao longo do século XX, pesquisas de cunho antropológico foram sendo realizadas em todas as regiões do Brasil, junto aos mais diversos coletivos, grupos, povos e comunidades, realizadas inicialmente por estrangeiras/os seguidas/os por brasileiras/os. Muito se sabe sobre a constituição do campo disciplinar no Sudeste e no Sul do Brasil, onde se encontram também os principais polos universitários e os grandes centros urbanos. Pode-se até dizer que os estudos sobre o campo nessas regiões austrais do Brasil se desenvolveram na medida em que se consolidaram os programas de pós-graduação em antropologia ou em ciências sociais com áreas de concentração em antropologia nessas regiões. Inúmeros compêndios, coletâneas, recensões e "estados da arte" foram publicados nas últimas três ou quatro décadas contendo um grande número de informações sobre a história da instituição do campo da antropologia no Brasil, criando a sensação da existência de uma antropologia nacional, embora os textos pouco ou nada falassem da antropologia que se fazia ou que estava despontando fora ou para além desses eixos acadêmicos do Sudeste e do Sul do País (Correa,1987, 2003a, 2003b; Martins; Duarte, 2010; Melatti, 1983; Miceli, 1999, 2001, 2005; Salzano, 2009).

Aos poucos, foi-se descrevendo timidamente a extensão do campo para as regiões Nordeste, Norte e para o resto do Centro-Oeste, para além de Brasília, talvez, aqui também, em função da fortíssima expansão da pós-graduação e da graduação nessas regiões (Almeida, 2019; Grossi; Tassinari; Rial, 2006; Lima et al., 2018; Trajano Filho; Ribeiro, 2004; Simião; Feldman-Bianco, 2018).

No Piauí, faltava, até a montagem do Programa de Pós-Graduação em Antropologia e Arqueologia (PPGAArq) da Universidade Federal do Piauí (UFPI), no final da década de 2000, uma história da constituição do campo antropológico no estado ${ }^{4}$ O autor e a autora se dedicaram a esse trabalho em 2008, com vistas à elaboração da Apresentação de Propostas de Cursos Novos

\footnotetext{
${ }^{3}$ Uma versão reduzida desse artigo foi publicada por Gontijo (2015), na Revista FSA - Tonny Rodrigues, o editor da revista autorizou a sua republicação atualizada.

${ }^{4}$ Não se trata, aqui, de abordar os trabalhos antropológicos que foram realizados no Piauí - como os trabalhos pioneiros de Carneiro (1976) e Godoi (1999), dentre outros -, mas de iniciar uma reflexão sobre a formação do campo antropológico no estado a partir de pesquisadores/as que permaneceram ali e se vincularam a instituições locais, estabelecendo localmente, assim, esse campo.
} 
(APCN) do PPGAArq/UFPI, juntamente com algumas/ns colegas do Departamento de Ciências Sociais da UFPI, dentre os quais Fábio Ferreira, Junia Napoleão e Ferdinand Cavalcante ${ }^{5}$.

Ao que parece, os campos da antropologia e da arqueologia se institucionalizaram concomitantemente no Piaú - por mãos de mulheres pesquisadoras -, o que pode ser uma pista para se entender a peculiaridade da história da antropologia no estado. Com a instalação da Missão Arqueológica Franco-Brasileira e a criação do Núcleo de Antropologia Pré-Histórica (NAP) na UFPI, em fins da década de 1970, liderado pela arqueóloga paulista Niède Guidon, desenvolveramse as pesquisas arqueológicas. De outro lado, alastraram-se o ensino e a pesquisa em antropologia com a criação, no início da década de 1980, do Departamento de Ciências Sociais da UFPI, tendo em seu quadro, na área de antropologia, uma participante da equipe de Niède Guidon, a etnóloga, também paulista, Vilma Chiara, além de Elda Arêa Leão e Maria do Carmo Veloso. Assim, a antropologia e a arqueologia, no Piauí - talvez mais claramente do que em outras unidades da Federação -, possuem uma genealogia acadêmica feminina simultânea e relativamente conectada que marcaria a história do desenvolvimento desses campos disciplinares em suas origens, embora deva-se pensar com cautela em uma possível "linhagem" comum.

Até a institucionalização da antropologia e da arqueologia no Piauí, o interesse pela diversidade cultural e pela história da ocupação e dos povos que viveram no estado era suprido pelos estudos realizados por pensadores, sábios diversos e homens de letras, sobretudo historiadores, fossem eles amadores diletantes ou cientistas apaixonados (sim, sempre eles, e nunca elas). Relatos retratando fragmentos de certa realidade piauiense são encontrados nas obras de inúmeros missionários, viajantes, desbravadores e administradores coloniais dos séculos XVI a XIX, dentre os quais Claude d'Abbeville (História da Missão dos Padres Capuchinhos na Ilha do Maranhão e Terras Circunvizinhas), Rouloux Baro (Relação da Viagem de Rouloux Baro [...] ao País dos Tapuias), Yves d'Evreux (Viagem ao Norte do Brasil Feita nos Annos de 1613 e 1614), Gabriel Soares de Sousa, Affonso d'Escragnolle Taunay, Johann Baptist Von Spix e Karl Friedrich Philip Von Martius, dentre tantos outros ${ }^{6}$.

Ao longo do período que vai do final do século XIX ao início do XX, várias obras que marcaram uma literatura genuinamente piauiense discorreriam sobre a realidade sertaneja, em particular aquele que é considerado (Silva, 2005) um dos primeiros romances de seca na literatura brasileira, Ataliba, o Vaqueiro, de Francisco Gil Castelo Branco, e as poesias contidas em A Lira

\footnotetext{
${ }^{5}$ Grande parte das informações contidas nesse artigo são oriundas das inúmeras conversas com esses/as professores/as, aos/às quais agradecemos pelo esforço da memória.

${ }^{6}$ Trata-se de um conjunto de textos publicados em diversas edições ao longo dos últimos séculos e de fácil acesso, via internet, em sites especializados, razões pelas quais preferimos omiti-las das referências bibliográficas.
} 
Sertaneja, de Hermínio Castelo Branco, além de romances que retratam a diversidade cultural e a desigualdade social urbana teresinense, como em O Manicaca, de Abdias Neves. Em El Matador, do poeta H. Dobal, denunciava-se o massacre da população indígena do estado durante o processo de ocupação no século XVIII, perpetrado por pecuaristas da Casa da Torre de Garcia d'Ávila. Em seguida, ainda na literatura, seriam nomeadas as desigualdades sociais de raça e gênero, em particular na obra do poeta vanguardista e fundador do Movimento Tropicália, Torquato Neto, já nas décadas de 1960 e 70 do século XX.

Dois grandes pensadores sociais - historiadores - desenvolveriam, em suas obras publicadas ao longo do século XX, um poderoso paradigma para a compreensão da ocupação do Piauí e, particularmente, das relações entre populações nativas, invasores europeus e africanas/os escravizadas/os: Odilon Nunes, em seu clássico Pesquisas para a História do Piauí, e Monsenhor Chaves (Joaquim Raimundo Ferreira Chaves), em seu antológico O Índio no Solo Piauiense. Dois heróis populares, mártires "etnicamente marcados", seriam objetos de interesse de várias/os historiadoras/es e literatas/os: Mandu Ladino, o índigena que, em solo piauiense, reuniu uma confederação de "tribos" para se rebelar contra as invasões "brancas" no século XVIII; e Esperança Garcia, a negra escravizada que, depois de conseguir com muito custo a tão sonhada liberdade, juntou negras/os, indígenas e brancas/os despossuídas/os para resistir à opressão colonial.

Uma obra curiosa, Fenícios no Brasil (Antiga História do Brasil - De 1100 a. C. 1500 d. C.), seria tema de discussões acirradas no meio acadêmico brasileiro e mundial: no início do século $\mathrm{XX}$, o historiador e filólogo austríaco Ludwig Schwennhagen, em visita à região do que é hoje o Parque Nacional de Sete Cidades, na região norte do estado, afirmaria ter encontrado vestígios de uma civilização pré-colonial originária dos fenícios, “demonstrando" a antiguidade do povoamento dessa área das Américas. A comunidade científica nunca conseguiria comprovar essa tese, mas esse tipo de ficção se mostrava típico desse momento da "era dos museus", entre o final do século XIX e o início do século XX, em que se buscavam vestígios de civilizações "avançadas" no Brasil para legitimar a viabilidade do projeto nacional em construção (Ferreira, 2009; Schwarcz, 2005).

Outras obras importantes trariam mais precisão sobre as relações sociais na história do Piauí, como O Vale do Rio Parnaíba, de Jacob Manoel Gayoso e Almendra, Roteiro do Piauí, de Carlos Eugênio Porto, O Povoamento do Piauí, de Moysés Castelo Branco Filho e, principalmente, Etnohistória Indígena Piauiense, de João Gabriel Batista e Piauí Colonial, de Luiz R. B. Mott. Importantes teses de doutorado e dissertações de mestrado, defendidas nos últimos 30 anos, têm trazido novidades relevantes para o estudo do povoamento do Piauí, algumas defendidas, no final da década de 2000, no Programa de Pós-Graduação em História do Brasil, da UFPI, como as teses das historiadoras, antropólogas e arqueólogas Junia Napoleão e Jóina Freitas Borges, assim como a tese e a obra enciclopédica da historiadora Claudete Miranda Dias e a tese da arqueóloga e 
historiadora Gisele Daltrini Felice. Vale destacar ainda os trabalhos de etnohistória indígena empreendidos pelo historiador João Renôr Ferreira de Carvalho (Os Índios Gueguê e Acaroa (Craô) do Piaui Colonial) e pelo jurista e escritor Paulo Machado (As Trilhas da Morte: Extermínio e espoliação das nações indígenas na região da Bacia Hidrográfica Parnaibana Piauiense).

No que diz respeito mais especificamente à antropologia e à arqueologia, parece que, de fato, Niède Guidon e Vilma Chiara é que historicamente teriam inaugurado as pesquisas nessas áreas, tendo o Piauí como contexto temático de trabalho. Niède Guidon ${ }^{7}$, nascida em São Paulo no início da década de 1930, cursou História Natural na Universidade de São Paulo (USP) entre 1956 e 1959, especializou-se em Arqueologia Pré-Histórica na Universidade de Paris IV/Sorbonne (Université de Paris IV), nos anos de 1961 e 1962, doutorou-se em Pré-História na Universidade de Paris I/Panthéon-Sorbonne (Université de Paris I), entre 1971 e 1975, e concluiu um estágio de pósdoutorado, também na Universidade de Paris I, em 1984.

Quando era pesquisadora do Museu Paulista (USP), no início da década de 1960, Niède Guidon parece ter sido informada por um representante político de São Raimundo Nonato, de que naquela região do semiárido piauiense haviam sido encontrados inúmeros indícios da presença humana que poderiam ser pré-coloniais, por meio dos desenhos e grafismos feitos por chamados “caboclos” (Borges, 2007) em grutas ocupadas, àquela época, por grupos familiares de caçadores/as empobrecidos/as - ou talvez quilombolas. Algum tempo depois, a pesquisadora conseguiria ir verificar in loco do que se tratava. Surpresa com as descobertas, transformaria os registros rupestres ali vistos em objeto de pesquisa para o seu doutorado, no início da década de 1970, juntaria uma equipe de arqueólogos/as e antropólogos/as experientes, servir-se-ia de seu prestígio junto ao Centro Nacional de Pesquisa Científica francês (Centre National de la Recherche Scientifique, CNRS) e junto à Organização das Nações Unidas para a Educação, a Ciência e a Cultura (United Nations Educational, Scientific and Cultural Organization, UNESCO) e, com o apoio do Ministério das Relações Exteriores francês (Ministère des Affaires Étrangères), estabeleceria a "Missão Franco-Brasileira no Sudeste do Piauí” para empreender o gigantesco trabalho de mapeamento, catalogação e estudo dos sítios arqueológicos da região da Serra da Capivara, em parceria com a UFPI, através da criação, em 1978, do Núcleo de Antropologia Pré-Histórica (Borges, 2007).

\footnotetext{
${ }^{7}$ As informações apresentadas a partir daqui sobre Niède Guidon, que podem conter alguns erros pelos quais pedimos de antemão desculpas, foram compiladas a partir de conversas com professoras/es da UFPI (dentre as/os quais algumas/ns que estavam na base da criação do Programa de Pós-Graduação em Antropologia e Arqueologia), do currículo da Plataforma Lattes e de inúmeras entrevistas concedidas pela pesquisadora em revistas, jornais e canais de televisão, além da dissertação de Mestrado de Síria Emerenciana Nepomucemo Borges, defendida em 2007 junto ao Programa de Pós-Graduação em História do Brasil da UFPI (Borges, 2007).
} 
Por sua vez, Vilma Chiara ${ }^{8}$, nascida em São Paulo, no final da década de 1920, formou-se em Economia Política na Escola Livre de Sociologia e Política de São Paulo (ELSP), na primeira metade da década de 1950, graduou-se em Etnologia na Universidade de Paris I/Panthéon-Sorbonne (Université de Paris I), na França, e realizou o mestrado e o doutorado em Etnologia, na Escola de Altos Estudos em Ciências Sociais (École des Hautes Études en Sciences Sociales), também na França, entre o final da década de 1960 e a década seguinte. Logo após a graduação, teria sido convidada por Sérgio Buarque de Holanda, então diretor do Museu Paulista, e por Herbert Baldus, chefe do Setor de Etnologia do Museu (considerado "o papa da Etnologia Brasileira", nas palavras de Vilma Chiara $^{9}$ ), para ali estagiar.

No Museu Paulista, teria conhecido o fotógrafo e etnólogo Harald Schultz, braço direito de Baldus, ex-chefe do Serviço de Documentação Fotocinematográfica e Sonora do Serviço de Proteção ao Índio (SPI). Schultz havia sido orientado pelo Marechal Rondon no SPI; em seguida, foi iniciado em Etnologia por Curt Nimuendajú e, enfim, aluno de Baldus na Escola Livre de Sociologia e Política de São Paulo. No Museu, Schultz retomaria a publicação da Revista do Museu Paulista e incentivaria a tradução de etnólogos alemães e teuto-brasileiros, como Paul Ehrenreich. Vilma Chiara se casou com Harald Schultz e o acompanharia em suas expedições por diversos territórios indígenas brasileiros até enviuvar, em 1966.

A primeira dessas viagens, que soaria como "viagem de núpcias", levaria o casal à cidade de Belém, no Pará, de onde partiriam para uma expedição até a divisa do Acre com o Peru, permanecendo junto aos indígenas Tukurina durante alguns meses. Um ano depois, após a chegada em São Paulo, nasceria o filho do casal, que acompanharia os pais em viagens aos territórios dos Karajá, às margens do Rio Araguaia. No início da década de 1960, como funcionária do Museu Paulista, a vida de mãe e de profissional prosseguiria com dificuldades. No Museu Paulista, começariam a se acumular as coleções de peças indígenas que deviam ser catalogadas, restauradas e preparadas para exposições para torna-las acessíveis ao público, o que demandava mais pesquisas, publicações, logo, mais viagens. Nesse roldão de atividades, surgiria a oportunidade de uma viagem aos Estados Unidos para uma formação museológica apoiada pelos arqueólogos Clifford Evans e Betty Meggers, junto à Organização dos Estados Americanos (OEA), que duraria nove meses. Outros estágios seriam realizados em outras cidades e outros museus, em função da especialização de cada equipe museológica estadunidense.

\footnotetext{
${ }^{8}$ As informações apresentadas a partir daqui sobre Vilma Chiara, que também podem conter erros pelos quais desde já nos desculpamos, foram compiladas a partir de conversas com a própria Vilma Chiara (que mandou ao primeiro autor o seu currículo em outubro de 2007), conversas com professoras/es do Departamento de Ciências Sociais da UFPI, acesso ao site da antropóloga (https://vilmachiara.wordpress.com/curriculo/) e de inúmeras entrevistas disponíveis na internet (dentre as quais a que foi publicada na Revista Contato), além de textos sobre a biografia de Harald Schultz e de colegas de trabalho - em particular o artigo de Françozo (2005), o de Chiara (1991) e a dissertação de mestrado de Passador (2002).

${ }^{9}$ Em entrevista concedida à Revista Contato, $\mathrm{n}^{\circ}$ 53, ano 9, 2007.
} 
As atividades múltiplas e absorventes desenvolvidas sob a égide do Museu Paulista dificultariam o prosseguimento acadêmico de qualquer ordem, e o engajamento no curso de pósgraduação iniciado na Universidade de São Paulo, com os professores Egon Schaden e Florestan Fernandes, ficaria comprometido. Não obstante, além dos grupos étnicos contatados ao longo do Rio Purus e seus afluentes no Acre, seriam alinhavadas relações com os do alto Solimões (Tukuna), do Guaporé (Moré), do Araguaia (Karajá, Chambioá, Javahé, Tapirapé) e do Cerrado do Tocantins e Maranhão (Kraô, Canela). Ao longo dos doze anos de duração do casamento, Vilma Chiara teria visitado e estudado, dessa maneira, inúmeras sociedades indígenas, especializando-se, finalmente, na sociedade Kraô. Em 1966, com a morte de Schultz, herdaria um acervo de mais de 12.000 negativos, 10.000 slides e 60 filmes etnográficos retratando pelo menos 14 povos indígenas diferentes.

Depois da morte do marido, Vilma Chiara deixaria o Museu Paulista e se mudaria para a França, a convite da arqueóloga Annette Laming-Emperaire, em pleno auge do estruturalismo lévistraussiano. Em Paris, encontraria Niède Guidon, com quem já havia trabalhado no Museu Paulista. Prosseguiria sua formação acadêmica e concluiria finalmente o doutorado sobre os Kraô. Quando Niède Guidon foi para o Piauí para tratar dos vestígios arqueológicos de que lhe haviam falado, Vilma Chiara a ajudaria a criar a Missão Franco-Brasileira de Arqueologia como antropóloga assistente. Com mais um doutorado concluído, dessa vez em Geografia pela Universidade de São Paulo, e um Pós-Doutorado na Universidade de Harvard, seria integrada ao quadro docente de antropologia da UFPI. Ademais de seu interesse por etnologia indígena, empreenderia pesquisas, ao longo de mais de quase duas décadas de docência na UFPI, sobre as cosmologias de "civilizações ocidentais", em particular sobre o mito de origem bíblico, envolvendo, nesse projeto, muitas/os dos/as demais jovens antropólogas/os do Departamento de Ciências Sociais. Após a aposentadoria, em 1995, Vilma Chiara mudou-se para o Paraná.

Percebe-se, portanto, a importância de Niède Guidon e de Vilma Chiara, tanto para a institucionalização inicial dos campos disciplinares da arqueologia e da antropologia no Piauí, como para a estruturação teórico-metodológica desses campos, particularmente na UFPI, por meio da criação do Núcleo de Antropologia Pré-Histórica e da fundação da Associação de Pesquisadores em Ciências Humanas $(\mathrm{APeCH})$, que apoiaria academicamente o curso de Ciências Sociais ${ }^{10}$.

Consolidando os trabalhos de pesquisa na região, Niède Guidon iniciaria a formação da Fundação Museu do Homem Americano (FUMDHAM). A partir daí, o Parque Nacional da Serra da Capivara seria criado em 1979 e, alguns anos depois, o Instituto Brasileiro de Meio Ambiente e dos Recursos Naturais Renováveis (IBAMA) concederia à FUMDHAM a direção do Parque

\footnotetext{
${ }^{10}$ A arqueologia e a antropologias feitas no Piauí pareciam ser então marcadamente processualista e estruturalista, respectivamente, durante as décadas de 1970 e 1980.
} 
Nacional. Em 1991, o Parque seria reconhecido pela UNESCO como Patrimônio Cultural da Humanidade. Um outro Parque, também de reconhecido interesse arqueológico, seria criado alguns anos depois, o Parque Nacional da Serra das Confusões.

A FUMDHAM e o Parque Nacional da Serra da Capivara, tendo à frente Niède Guidon, realizariam cursos de formação, de capacitação e de especialização de profissionais para trabalhar, não somente com a conservação dos vestígios arqueológicos do Parque e adjacências, mas também para desenvolver pesquisas fundamentais e refletir sobre as formas de envolvimento das comunidades locais, através de ações de educação patrimonial, na preservação e na conservação cidadãs do patrimônio natural e cultural da região. Foi nesse contexto que ocorreu a criação de um escritório técnico do Instituto do Patrimônio Histórico e Artístico Nacional (IPHAN) em São Raimundo Nonato, assim como a estruturação do Museu do Homem Americano, a realização de inúmeros eventos artísticos e culturais, alguns de renome internacional (como as três edições do Festival Interartes, na primeira metade da década de 2000) e eventos científicos (como o encontro da International Federation of Rock Art Organization, IFRAO, em 2009), a implementação de um programa de Arte-Educação (Pró-Arte) e, finalmente, a execução de formação em dança, artes cênicas, cerâmica, etc, direcionada para a comunidade do entorno do Parque, dentre tantas outras ações e atividades ${ }^{11}$.

No âmbito da pesquisa científica, ao longo da década de 1990, a FUMDHAM se consolidou como instituição de excelência na área de arqueologia, estimulando parcerias com o Programa de Pós-Graduação em Arqueologia (Mestrado e Doutorado) da Universidade Federal de Pernambuco e, nos anos 2000, com o curso de graduação em Arqueologia da então recém-criada Universidade Federal do Vale de São Francisco. A partir de 2008, a FUMDHAM também abrigaria algumas atividades do curso de graduação em Arqueologia e Conservação de Arte Rupestre da UFPI, criado na segunda metade da década de 2000.

Com a instalação definitiva de Niède Guidon na primeira metade da década de 1980, nas proximidades da sede da FUMDHAM, em São Raimundo Nonato, a parceria com a UFPI passou a ser representada pela geração então formada pela pesquisadora, membros do Núcleo de Antropologia Pré-Histórica (NAP), e pela etnóloga Vilma Chiara, da área de antropologia do Departamento de Ciências Sociais (DCS). Integraram o DCS, fortalecendo a relação entre arqueologia e antropologia, desde a sua criação, os arqueólogas/os e antropólogas/os Sônia Campelo (Mestra em Pré-História, Etnologia e Antropologia pela Universidade de Paris I/Sorbonne

11 Veja, para mais informações sobre o Pró-Arte, <http://linadocarmo.de/112-2-Pr-Arte-Fumdham.html> e $<$ http://lucasaquiles.tripod.com/site_projeto/conteudo/arte.htm> e sobre a FUMDHAM, <http://www.fumdham.org.br>. 
e Doutora em História pela Universidade Federal Fluminense), Fábio Lustosa Ferreira (Especialista em Arqueologia pelo Museu Nacional da UFRJ, Mestre em Educação pela UFPI) e, posteriormente, Junia Napoleão (Especialista em Arqueologia pelo Museu Nacional da UFRJ, Mestra em Educação pela Universidade Estadual do Piauí, em parceria com o Instituto Pedagógico Latinoamericano y Caribeño de Cuba, e Doutora em História pela Universidade Federal Fluminense), além de Rose Mary Ribeiro (Mestra em Antropologia pela Universidade Federal de Pernambuco).

A antropologia seria reforçada ainda, ao longo dos anos 1990, com a atividade das antropólogas Maria Lídia Medeiros de Noronha Pessoa (Mestra em Antropologia Social pela Unicamp e Doutora em Teoria da Literatura pela Pontifícia Universidade Católica do Rio Grande do Sul), Maria do Carmo Veloso (hoje aposentada, Especialista em Economia Rural e Mestra em Gestão Universitária pela UFPI) e Elda Arêa Leão (atualmente também aposentada). Para suprir tanto as vagas abertas pelas aposentadorias, quanto a necessidade gerada pelo afastamento para doutoramento de outras/os docentes, foram contratadas/os Fabiano de Souza Gontijo, no início da década de 2000 (Mestre e Doutor em Etnologia e Antropologia pela Escola de Altos Estudo em Ciências Sociais, École des Hautes Études en Sciences Sociales, França), e, em seguida, Francisca Verônica Cavalcanti (Mestra e Doutora em Ciências Sociais, com ênfase em Antropologia, pela Pontifícia Universidade Católica de São Paulo).

A professora Maria Lídia Medeiros de Noronha Pessoa, em 1992, após a defesa de sua dissertação de mestrado na Unicamp, fundou na UFPI, junto com colegas do Departamento de Serviço Social e do Departamento de Ciências Sociais, o Núcleo de Pesquisa e Estudos sobre a Criança (NUPEC), com o apoio financeiro do Fundo das Nações Unidas para as Crianças (United Nations Children's Fund, UNICEF), além do Programa de Agentes Comunitários de Saúde (PACS) em parceria com a Fundação Nacional de Saúde. Ressalta-se a parceria profícua e instigante com a Prof $^{a}$ Dulce Silva, do Departamento de Serviço Social, à frente do NUPEC. Foram muito intensas e determinantes, para a antropologia piauiense, as atividades no NUPEC, tais como a produção acadêmica, a participação em fóruns e conselhos oficiais, a realização de eventos, a criação de um periódico (Cadernos NUPEC), etc. O NUPEC proporcionou a participação de discentes de diversos cursos em estágios curriculares e extracurriculares, além de promover diálogos entre discentes, docentes e pesquisadoras/es do Brasil e do exterior. O NUPEC estaria ainda na base das propostas de cursos de pós-graduação do Centro de Ciências Humanas e Letras da UFPI, tais como o curso de Mestrado em Antropologia e Arqueologia e os cursos de Mestrado e Doutorado em Políticas Públicas.

No final da década de 2000, reúnem-se para a criação de um curso de Pós-Graduação em Antropologia, em associação com o Programa de Pós-Graduação em Sociologia e Antropologia da Universidade Federal do Rio de Janeiro (UFRJ), as Profas. Maria Lídia Medeiros de Noronha 
Pessoa e Francisca Verônica Cavalcante, com o Prof. Fabiano de Souza Gontijo. O curso viria a ser recomendado pela Coordenação de Aperfeiçoamento de Pessoal do Ensino Superior (CAPES) somente em 2008, para iniciar suas atividades em 2009, mas agora sem a associação com a UFRJ e com a proposta de um Programa de Mestrado contendo as áreas de concentração em Antropologia e em Arqueologia, representativo da "cara" da própria configuração dos dois campos disciplinares no estado. O curso contou, em sua formação inicial, com a participação, na área de antropologia, das/os Profas/s. permanentes Maria Lídia Medeiros de Noronha Pessoa, Francisca Verônica Cavalcante, Fabiano de Souza Gontijo, Ferdinand Cavalcante Pereira (Doutor em Sociologia pela Universidade Federal do Rio Grande do Sul), Francisco de Oliveira Barros Júnior (Doutorado em Ciências Sociais pela Pontifícia Universidade Católica de São Paulo), Maria Dione de Carvalho Morais (Doutorado em Ciências Sociais pela Universidade Estadual de Campinas), Marlúcia Valéria Silva (Doutora em Sociologia Política pela Universidade Federal de Santa Catarina) e Mary Alves Mendes (Doutora em Sociologia pela Universidade Federal de Pernambuco), e das Profas. colaboradoras Ana Beatriz Sousa Gomes (Doutorado em Educação pela Universidade Federal do Ceará), João Renôr Ferreira de Carvalho (Doutor em Estudos Latino-Americanos pelo Instituto de Altos Estudos da América Latina, França) e Shara Jane Holanda Costa Adad (Doutora em Educação pela Universidade Federal do Ceará); e, na área de concentração em arqueologia, com as Profas. permanentes Maria Conceição Soares Meneses Lages (Doutora em Antropologia pela Universidade de Paris I-Panthéon-Sorbonne, França), Gisele Daltrini Felice (Doutora em História pela Universidade Federal de Pernambuco), Jacionira Coelho Silva (Doutora em História pela Universidade Federal de Pernambuco), e as colaboradoras Edithe Pereira da Silva (Doutorado em Arqueologia pela Universidade de Valência, Espanha) e Niède Guidon.

Com a criação do Programa de Pós-Graduação em Antropologia e Arqueologia (PPGAArq), iniciando suas atividades em 2009 sob a coordenação de Fabiano de Souza Gontijo e Maria Conceição Meneses Lage, foram contratados mais algumas/ns antropólogas/os e arqueólogas/os as/os primeiras/os lotadas/os no Departamento de Ciências Sociais e as/os outras/os na Coordenação de Arqueologia - dentre as/os quais, Alejandro González Labale (Doutor em Antropologia pela Universidade Federal de Santa Catarina), João Miguel Mazolillo Sautchuk (Doutor em Antropologia pela Universidade de Brasília), May Waddington Teles Ribeiro (Doutora em Desenvolvimento ) e Robson Rogério Cruz (Doutor em Sociologia e Antropologia pela Universidade Federal do Rio de Janeiro), além da arqueóloga Andrea Lourdes Monteiro Scabello (Doutora em Geografia pela Universidade de São Paulo). A antropologia e a arqueologia na UFPI contava com a colaboração de grande relevância de professoras/es-pesquisadoras/es com "trânsito livre" entre a sociologia e a antropologia, por um lado, como Maria Dione de Carvalho Morais, ou entre a arqueologia e as ciências naturais, por outro, como Maria Conceição Soares Meneses Lage. 
Alguns grupos de pesquisa, em sua maior parte cadastrados junto ao Conselho Nacional de Desenvolvimento Científico e Tecnológico (CNPq), foram fortalecidos ou criados para sustentar o novo Programa de Pós-Graduação, dentre os quais os grupos de Antropologia do Desenvolvimento e Meio Ambiente; Antropologia, Imagem e Patrimônio Cultural; Antropologia do Corpo, Gênero e Sexualidade; Ritual e Simbolismo; dentre outros, marcando os eixos temáticos privilegiados pelo novo PPGAArq, as pesquisas desenvolvidas, os eventos organizados e as dissertações defendidas em seu âmbito.

Algumas atividades do PPGAArq, em seus primeiros anos, merecem destaque para o desenvolvimento das pesquisas antropológicas e arqueológicas no Piauí:

1) a aprovação e o desenvolvimento do Programa de Cooperação Acadêmica, conhecido como PROCAD-NF, da CAPES, em conjunto com o Programa de Pós-Graduação de Ciências Sociais em Desenvolvimento, Agricultura e Sociedade (CPDA), da Universidade Federal Rural do Rio de Janeiro (UFRRJ), sob a coordenação das Profas. May Waddington Telles Ribeiro (PPGAArq/UFPI) e Maria José Carneiro (CPDA/UFRRJ), que proporcionou o financiamento de pesquisas sobre os impactos sociais e culturais dos grandes projetos de desenvolvimento agrícola em andamento no Piauí, envolvendo pesquisadoras/es do PPGAArq da UFPI e do CPDA da UFRRJ, além de estudantes de ambas as instituições, com a realização de estágios de mestrado sanduíche por parte das/os estudantes, estágios de pós-doutorado por parte das/dos docentes, eventos em ambas as instituições, etc; e

2) a parceria do PPGAArq com a superintendência estadual do Instituto do Patrimônio Histórico e Artístico Nacional (IPHAN), que proporcionou o desenvolvimento de importantes pesquisas envolvendo docentes e discentes, tais como aquelas referentes ao registro de bens imateriais (a arte santeira piauiense; a cajuína; o tambor de crioula; etc).

Com o crescimento da UFPI e a consolidação do PPGAArq, mudanças significativas ocorreram entre a primeira e a segunda metades da década de 2010, cabendo destaque para três delas que têm impacto sobre a antropologia entre a segunda metade da década e os dias de hoje:

1) a criação do Programa de Pós-Graduação em Sociologia e o credenciamento de docentes do PPGAArq no novo Programa, algumas/ns delas/es se retirando do PPGAArq definitivamente ou se tornando docentes colaboradoras/es;

2) a saída de docentes da UFPI para aturarem em outras instituições (Fabiano de Souza Gontijo para a Universidade Federal do Pará, João Miguel Sautchuk para a Universidade de Brasília, May Waddington Telles Ribeiro para a Universidade Federal do Sul da Bahia e Robson Cruz para a Universidade Federal da Integração Internacional da Lusofonia Afro-Brasileira) e a incorporação de novas/os docentes nessas vagas ociosas e em outras vagas de concursos, além de pós-doutorandas/os, dentre as quais as Profas. Carmen Lúcia Silva Lima (Doutora em Antropologia 
pela Universidade Federal de Pernambuco), Celso de Brito (Doutor em Antropologia pela Universidade Federal do Rio Grande do Sul), Carlos Roberto Filadelfo de Aquino (Doutor em Antropologia pela Universidade de São Paulo), Jóina Freitas Borges (Doutora em História pela Universidade Federal Fluminense), Marcia Leila de Castro Pereira (Doutora em Antropologia pela Universidade de Brasília), Monica da Silva Araújo (Doutora em Antropologia pela Universidade Federal do Rio de Janeiro, Museu Nacional), Raimundo Nonato Ferreira do Nascimento (Doutor em Antropologia pela Universidade Federal de Pernambuco), dentre outras/os; e, enfim,

3) algumas questões teóricas e metodológicas levaram ao desmembramento da linha de pesquisa mais voltada para a arqueologia do PPGAArq, desembocando na criação do Programa de Pós-Graduação em Arqueologia, vinculado ao Centro de Ciências da Natureza; no Centro de Ciências Humanas e Letras, continuou funcionando a formação pós-graduada em antropologia no renomeado Programa de Pós-Graduação em Antropologia (PPGAnt); essa foi uma importante ocasião para a realização de mudanças no quadro docente do Programa, adequando-o ainda mais às demandas piauienses, com a incorporação de novas/os docentes.

$\mathrm{Na}$ Universidade Estadual do Piauí (UESPI), assim como nos campi interioranos da UFPI, na nova Universidade Federal do Delta do Parnaíba e nas instituições privadas de ensino superior, onde disciplinas de antropologia são ministradas em cursos das mais diversas áreas do conhecimento, as/os docentes encontram certa dificuldade em incentivar a realização de pesquisas, por diversas razões, geralmente de ordem financeira e logística, embora muitas/os sejam doutoras/es. Essa realidade pode vir a mudar com as recentes contratações de professoras/es doutoras/es em campi interiorizados da UFPI e na Universidade Federal do Delta do Parnaíba, e com a abertura de mais um curso de Ciências Sociais na UESPI, somados ao já existente na UFPI. Por essas razões, a produção em antropologia ainda se concentra em grande parte no PPGAnt da UFPI.

$\mathrm{Na}$ primeira metade da década de 2010, as pesquisas antropológicas piauienses parecem marcadas por dois grandes eixos temáticos: por um lado, têm-se os estudos sobre as múltiplas formas de ruralidades e os direitos das comunidades tradicionais, em particular (mas, não somente) incentivadas pela implementação do um vasto programa de pesquisa do PROCAD-NF, já citado acima; e, por outro, os estudos sobre as intersecções de marcadores sociais da diferença, tais como gênero, sexualidade, geração/idade e regionalidade, geralmente em contextos urbanos, em suas interfaces com os estudos de patrimônio, os estudos de religiosidade, a psicanálise, etc.

Na segunda metade da década de 2010, a reconfiguração do PPGAnt da UFPI acrescenta e/ou reforça temáticas que passam a marcar ainda mais a antropologia piauiense, tais como: a etnologia indígena, os processos étnicos e as formas de etnogênese; a reconstituição da historiografia indígena no estado; os processos de territorialização quilombola; os conflitos 
socioambientais no contexto de definições fundiárias e demandas por direitos territoriais de povos e comunidades tradicionais; os estudos sobre corporalidades e esportes; as conexões entre psicanálise e antropologia, etc; a antropologia estadual ganha cada vez mais visibilidade a nível nacional, em particular com a criação da revista do PPGAnt, EntreRios.

Em síntese, parece que as preocupações antropológicas diletantes no Piauí eram supridas por pensadores sociais e historiadores até a ancoragem da arqueologia no estado com os grandiosos projetos empreendidos por Niède Guidon e sua equipe no final da década de 1970 e início da década de 1980. Um dos membros da equipe, Vilma Chiara, ajudou a fundar a antropologia “científica", de inspiração estruturalista, na UFPI, no início da década de 1980. Porém, em pouco tempo, ao longo da década de 1980 e sobretudo 1990, os dois campos disciplinares parecem ter divergido, fazendo com que não se perceba sequer que um dia possam ter caminhado juntos - vale lembrar que as perspectivas epistemológicas adotadas tinham dificuldade em conjugar antropologia e arqueologia, sobretudo com as preocupações da arqueologia da equipe de Niède Guidon contradizendo as novas preocupações interpretativistas da antropologia de Vilma Chiara.

Enfim, se, na década de 1990 e início de 2000, a formação e, por conseguinte, a pesquisa em antropologia pareciam moribundas, há uma importante flexão em meados da década. A partir da segunda metade da década de 2000, com o início da renovação do quadro docente da UFPI - devida em parte ao Programa de Apoio a Planos de Reestruturação e Expansão das Universidades Federais, REUNI - e a criação do curso de graduação em arqueologia, há uma nova e curta reaproximação dos campos que desemboca na formação do Programa de Pós-Graduação em Antropologia e Arqueologia, de inspiração levemente boasiana, e, em seguida, a criação do Programa de PósGraduação em Arqueologia, fortemente marcado pela formação em ciências naturais por parte de seus docentes. Na década de 2010, as inspirações teóricas e metodológicas se deslocam para uma antropologia com matizes diversas, ancorada na necessidade de se produzir reflexões sobre as rápidas transformações pelas quais o estado vem passando.

A produção antropológica agora se dá, desde a segunda metade da década de 2010, principalmente junto ao Programa de Pós-Graduação em Antropologia, responsável pela profissionalização de jovens pesquisadoras/es que, além de ocuparem as funções no magistério público e privado, atuam em organizações não-governamentais e instâncias governamentais, em particular no âmbito de pesquisas voltadas para a promoção dos direitos dos povos e comunidades tradicionais e para a compreensão das dinâmicas dos marcadores sociais da diferença. Vale ressaltar a predominância feminina na constituição do campo da Antropologia, desde seus primórdios, marcando a particularidade da transmissão e da formação em antropologia no estado. 
Enfim, Jimeno $(2004 ; 2007)$ descreve como particularidade das antropologias latinoamericanas o forte envolvimento das/os pesquisadoras/es com as comunidades, coletivos e grupos junto aos quais realizam as pesquisas com o intuito de refletir criticamente sobre os projetos nacionais. Para a autora, a missão das antropologias nessa área do mundo sempre foi a de questionar as bases ideológicas do Estado nacional e da diferença colonial persistente. A antropologia produzida no Piauí se associa obviamente à antropologia nacional, com a marca das antropologias latino-americanas, em sua tentativa de dar conta das dinâmicas culturais locais para ajuizar sobre os impactos dos projetos nacionais sobre as realidades regionais e a consequente opressão gerada. As novas narrativas sobre a história da antropologia brasileira deveriam levar em consideração, para serem mais completas para além do eixo Centro-Sul do país, não somente as particularidades locais da produção de conhecimentos antropológicos e a especificidade regional do funcionamento do campo disciplinar e acadêmico, mas também a sua associação com as lógicas nacionais de legitimação da produção científica e de implementação de modos duradouros de colonialismos internos. Fica a dica.

\section{REFERÊNCIAS}

AlMEIDA, A. W. B. Os Programas de Pós-Graduação em Antropologia na Amazônia. Rio de Janeiro: ABA, 2019.

BARTH, F., GRINGICH, A., PARKIN, R., SILVERMAN, S. One Discipline, Four Ways: british, german, french, and american anthropology. Chicago/Londres: University of Chicago Press, 2005.

BORGES, S. E. N A Invenção do Patrimônio Mundial: Parque Nacional da Serra da Capivara-PI. Teresina, 2007. Dissertação (Mestrado em História do Brasil) - Universidade Federal do Piauí, 2007.

CARDOSO DE OLIVEIRA, R. O Movimento dos Conceitos na Antropologia. Revista de Antropologia, v. 36, p. 13-31, 1995. Disponível em: $<$ http://www.revistas.usp.br/ra/article/view/111381 $>$.

CARNEIRO, M. J. Terra da Probreza. Rio de Janeiro, 1976. Dissertação (Mestrado em Antropologia Social) - Programa de Pós-Graduação em Antropologia Social, Universidade Federal do Rio de Janeiro, 1976.

CHIARA, V. Harald Schultz. In: WINTERS, C. (Org.). International Dictionnary of Anthropologists. Nova York/Londres: Garland Publishing, 1991. p. 623-624.

CORREA, M. (Org.). História da Antropologia no Brasil (1930-1960). Campinas: EdUnicamp, 1987.

CORREA, M. Antropólogas e Antropologia. Belo Horizonte: EdUFMG, 2003a.

CORREA, M. As Reuniões Brasileiras de Antropologia: 50 anos (1953-2003). Campinas: EdUnicamp / Brasília: ABA, 2003b.

CORREA, M. História da Antropologia no Brasil - Projeto da Unicamp. S/d - entrevista com Vilma Chiara. 
FERREIRA, L. M. "Ordenar o Caos": Emilio Goeldi e a Arqueologia Amazônica. In: Boletim do Museu Paraense Emilio Goeldi. Ciências Humanas, v. 4, n. 1, p. 71-91, 2009. Disponível em: $<$ http://scielo.iec.gov.br/pdf/bmpegch/v4n1/v4n1a07.pdf $>$.

FRANÇOZO, M. O Museu Paulista e a História da Antropologia no Brasil entre 1946 e 1956. Revista de Antropologia, v. 48, n. 2, p. 485-612, 2005. Disponível em: $<$ https://www.scielo.br/scielo.php?script=sci arttext\&pid $=$ S0034-

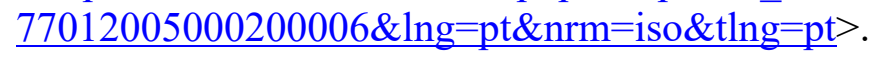

GODOI, E. P. O Trabalho da Memória. Campinas: EdUnicamp, 1999.

GONTIJO, F. Antropologia Fora dos Eixos? Algumas Considerações sobre as Particularidades da Formação de um Campo de Pesquisas no Piauí, Brasil. Revista FSA, v. 12, n. 5, p. 49-62, 2015.

Disponível em: $<$ http://dx.doi.org/10.12819/2015.12.5.3 $>$.

GROSSI, M.; TASSINARI, A; RIAL, C. (Orgs.). Ensino de Antropologia no Brasil. Blumenau: Nova Letra, 2006.

JIMENO SANTOYO, M. Naciocentrismo: tensiones y confinguración de estilos en la antropología sociocultural colombiana". Revista Colombiana de Antropología, v. 43, p. 9-32, 2007. Disponível em: $<$ http://www.scielo.org.co/pdf/rcan/v43/v43a01.pdf $>$.

JIMENO SANTOYO, M. La Vocación Crítica de la Antropología Latinoamericana. Maguaré, v. 18, p. 33-58, 2004. Disponível em: $<$ https://revistas.unal.edu.co/index.php/maguare/article/view/10833/11317>.

LIMA, A. C. S. et al. (Orgs.). A Antropologia e a Esfera Pública no Brasil. Brasília ABA, 2018.

MARTINS, C. B.; DUARTE, L. F. D. (Org.). Horizontes das Ciências Sociais: Antropologia. São Paulo: Anpocs, 2010.

MELATTI, J. C. Antropologia no Brasil: um roteiro. Série Antropologia - UnB, v. 38, 1983.

MICELI, S. (org.) O Que Ler na Ciência Social Brasileira (1970-1995): Antropologia (Volume I). São Paulo: Sumaré / ANPOCS /CAPES, 1999.

MICELI, S. (org.) História das Ciências Sociais no Brasil. Vol.1. São Paulo: Sumaré, 2001.

PASSADOR, L. H. Herbert Baldus e a Antropologia no Brasil. Campinas, 2002. Dissertação (Mestrado em Antropologia) - Universidade Estadual de Campinas, 2002.

PEIRANO, M. A Guide to Anthropology in Brazil. In: Vibrant, v. 2, 2005. Disponível em: $<\underline{\text { http://www.vibrant.org.br/issues/v2n1/mariza-peirano-a-guide-to-anthropology-in-brazil/>> }}$.

RIBEIRO, G. L. Antropologias Mundiais: para um novo cenário global na antropologia. Revista Brasileira de Ciências Sociais, v. 21, n. 60, p. 147-185, 2006. Disponível em: $<\underline{\text { https://www.scielo.br/scielo.php?script=sci_arttext\&pid=S0102-69092006000100009>. }}$.

SALZANO, F. A Antropologia no Brasil: é a interdisciplinaridade possível? Amazônica, v. 1, n. 1, p. 12-27, 2009. Disponível em: <https://periodicos.ufpa.br/index.php/amazonica/article/view/133/197>.

SCHWARCZ, L. M. A "Era dos Museus de Etnografia" no Brasil: o Museu Paulista, o Museu Nacional e o Museu Paraense em finais do XIX. In: FIGUEIREDO, B. G.; VIDAL, D. G. (Orgs.). Museus: dos gabinetes de curiosidades à museologia moderna. Belo Horizonte: Argvmentvm / Brasília: CNpq, 2005. p. 113-136.

SCHWENNHAGEN, L. Fenícios no Brasil (Antiga História do Brasil-De 1100 a. C. 1500 d. C.). Rio de Janeiro: Cátedra, 1986.

SILVA, R. C. M. A Representação da Seca na Narrativa Piauiense: séculos XIX e XX. Rio de Janeiro: Caetés, 2005. 
SIMIÃO, D.; FELDMAN-BIANCO, B. (Orgs.). O Campo da Antropologia no Brasil: retrospectiva, alcances e desafios. Rio de Janeiro: ABA, 2018.

TRAJANO FILHO, W.; RIBEIRO, G. L. (Orgs.). O Campo da Antropologia no Brasil. Rio de Janeiro: Contra Capa / ABA, 2004. 